\title{
Targeting Stem Cell Protein BMI1; A Potential Therapeutic Approach for Prostate Cancer Therapy \\ Firdous H Beigh ${ }^{1}$, Nidda Syeed ${ }^{2}$, Mohsin Maqbool ${ }^{3}$ and Rita Singh Majumdhar ${ }^{1^{*}}$
}

'Departments of Biotechnology, Sharda University, Greater Noida, India

${ }^{2}$ Department of Biotechnology, JMI, New Delhi, India

${ }^{3}$ Department of Medical Oncology, IRCH, AIIMS, New Delhi, India

\begin{abstract}
Prostate cancer $(\mathrm{CaP})$ is considered as a vexing challenge for clinical management because of its resistance to the conventional therapies, resulting in most deaths from this disease. The current treatment options including castration shows minimal effect, as most of the patients develop resistance and relapse of more aggressive Castration Resistant Prostate Cancer (CRPC). BMI1 (B cell-specific Moloney murine leukemia virus integration site 1), an oncogenic member of the polycomb group gene family and a transcriptional repressor has emerged as a key regulator in numerous processes including proliferation, differentiation, senescence, and stem cell renewal. Accumulating evidences have also revealed a relationship between BMI1 expression and the clinical grade/stage, therapy response, and survival outcome in most human malignancies, including Prostate cancer. Therefore, in this review, we provide the significant evidences suggesting the potential of BMI1 as a therapeutic target in the management of prostate cancer.
\end{abstract}

Keywords: BMI1; Prostate cancer; Chemoresistance; Cancer stem cells

\section{Introduction}

Prostate cancer $(\mathrm{CaP})$ is the most common cancer worldwide and leading cause of cancer death in men in the United States [1]. CaP after metastasis become highly resistant to the conventional therapies. The conventional therapy options including castration, especially in the advance metastatic disease, do not have an appreciable effect, as the patients display characteristic progression to aggressive Castration Resistant Prostate Cancer [CRPC] [2,3]. The cytotoxic chemotherapy for CRPC patients marginally extend the median survival by 2.9 months $[4,5]$. There is an evidence suggesting that only $25 \%$ of patients with metastasis live 5 years subsequent to the initial diagnosis of metastasis. Given this scenario, there is an ample need to understand better the etiology of this fatal disease, to develop more sensitive diagnostic means, and to identify potential therapeutic targets.

There is an increasing evidence that the polycomb group transcriptional repressor BMI1 (B cell-specific Moloney murine leukemia virus integration site 1), plays a pivotal role in stem cell selfrenewal and cancer development [6]. BMI1 belongs to the family of PcG proteins. PcG proteins are multimeric complexes involved in mediating histone modifications of explicit set of genes during cell development [7]. The BMI1 gene in humans is localized on the short arm of chromosome 10 (10p11.23), and the encoded protein is ubiquitously expressed in almost all tissues, with high expression levels in the brain, esophagus, salivary gland, thymus, kidney, lungs, gonads, placenta, blood, and bone marrow [8]. Several reports have documented that the BMI1 plays a crucial role in numerous cellular processes including cell proliferation, immortalization, and senescence [9]. The expression of BMI1 has been found to be upregulated in various human cancers, including, liver, head and neck, nasopharyngeal, prostate, colorectal, breast, endometrial, cervical, and ovarian cancers. Furthermore, a substantial correlation of abnormal BMI1 expression with the clinical grade/stage of the disease has been seen, signifying the promising potential for BMI1 to be a therapeutic target and prognostic marker of numerous cancers $[7,10-18]$. In the current review, we attempt to discuss the recent advancements in understanding the function and role of BMI1 in promoting tumorigenesis. We focus on the involvement of
BMI1 in the prostate cancer development, and the associated advances in clinical application.

\section{BMI1; Structure and Function}

BMI1, first identified in B cell lymphoma, is located on chromosome 10 [10p11.23]. The gene encodes a $37 \mathrm{kDa}$ protein comprising of 326 amino acids. Structurally, the BMI1 protein is characterized by three primary functional regions: a central Helix-Turn-Helix (HTH) domain, a conserved RING finger domain at the $\mathrm{N}$-terminal end, and a carboxylterminal PEST-like domain [9,19-20]. Besides the main three notable functional regions, the BMI1 protein also comprises of two nuclear localization signals (NLS): NLS1 and NLS2. Of these two, only NLS2 appears to be functional in nuclear localization of BMI1 [21].

BMI1 plays a key role in numerous cellular processes including differentiation, senescence, proliferation, and contributes to embryonic and stem cell self-renewal programs [22]. Various important polycomb repressive complex 1 target genes including Homeobox (HOX) genes and p16INK4a have been found to have certain interactive promoters elements, which can directly bind to BMI1 [16]. BMI1 controls the progression of cell cycle by regulating the important tumor suppressor proteins like p16INK4a and p14ARF, and promotes cell proliferation by suppressing the p16INK4a/retinoblastoma and/or the p14ARF/ MDM2/p53 pathways [23]. Initially, it was also shown that BMI1 is involved in cerebral development by regulating the hematopoiesis and differentiation of lymphocytes. BMI1 plays a pivotal role in maintaining the tissue homeostasis by regulating the self-renewal of neural, prostate, hematopoietic, intestinal, lung bronchioalveolar, and epithelial stem

${ }^{*}$ Corresponding authors: Prof. Rita Sing Mujamdhar, Prof \& Head Department of Biotechnology, Sharda University, India, Tel: 0120457 0000; E-mail: firdousbeigh@gmail.com

Received May 01, 2017; Accepted May 11, 2017; Published May 17, 2017

Citation: Beigh FH, Syeed N, Maqbool M, Majumdhar RS (2017) Targeting Stem Cell Protein BMI1; A Potential Therapeutic Approach for Prostate Cancer Therapy. J Stem Cell Res Ther 7: 388. doi: 10.4172/2157-7633.1000388

Copyright: @ 2017 Beigh FH, et al. This is an open-access article distributed unde the terms of the Creative Commons Attribution License, which permits unrestricted use, distribution, and reproduction in any medium, provided the original author and source are credited. 
cells [9,24-26]. Several reports have documented that the BMI1 protein inhibits the senescence and immortalize cells by maintaining the telomerase activity in adult stem cells [15]. Moreover, BMI1 is involved in protecting the DNA against oxidative DNA damage, and has been a key component of DNA Damage Repair (DDR) machinery, as it is actively involved in recruiting the DDR machinery to DNA Double Strand-Break (DSB) in response to damaging radiations [27]. Experimental evidence has also revealed that BMI1 is involved in inducing the Epithelial Mesenchymal Transition (EMT) by targeting the tumor suppressor PTEN [28].

\section{BMI1; Tumorigenicity and Cancer Stem Cells}

Several recent studies have suggested that BMI1 act as an oncogene, and its overexpression often promotes the tumorigenesis including breast, prostate, pancreas, lung, head and neck, urinary bladder, lymphoma, medulloblastoma, glioma, acute myeloid leukemia and ovarian cancer [29] as shown in Table 1.

Cancer Stem Cells (CSCs) are a stem cell-resembling population of cancer cells found in the mixture of cells constituting a tumor, which possesses the capacity of self-renewal and differentiation potential [30]. Apart from initiating the local tumor formation, the CSCs are also known to be involved in generating distant metastases [31]. Moreover, accumulating evidences have demonstrated that CSCs at various tumor sites, are spared by conventional cancer therapies, which typically target the tumor cells, leading to the relapse of tumor $[7,9,12,32]$. The paucity of knowledge about how the CSCs escape the traditional cancer therapy remains a stumbling block in management of various cancer diseases.

The advancements in the genetic and epigenetic profiling studies have enabled researchers to [i] unravel the molecular characteristics of human tumors in patients with early stage carcinoma of various origins, [ii] understand the mechanism of metastatic behavior and relapse of tumors post cancer therapy [29]. The activation of different molecules including BMI1 has been reported to be associated with CSCs induced cancer relapse [10,33]. Growing studies have shown the important function of BMI1 as a biomarker of CSCs [34]. The varied human malignancies have been attributed to the oncogenic activation of BMI1 [8-17,35-36]. Furthermore, various recent studies have revealed the functional relationship of BMI1 with the relevant pathways involved in regulating both stem and cancer cells.

BMI1, being a transcriptional repressor and PcG protein, plays an important role in maintaining and regulating self- renewal of adult stem cells. In some cancers, the dysregulation of BMI1 signalling has been linked to the activation of hedgehog pathway [37]. BMI1 regulates multiple pathways, most prominent of which is the induction of telomerase, leading to cell immortalization, such as in mammary epithelial cells [6]. BMI1 is also known to be involved in neoplastic transformation of lymphocytes in cooperation with $\mathrm{H}$-Ras during breast carcinogenesis. In addition, BMI1 coupled estrogen receptor a activity

\begin{tabular}{|c|c|c|}
\hline Type of Cancer & BMI1 status & Reference Number \\
\hline Prostate cancer & Overexpression & {$[29]$} \\
\hline Pancreatic cancer & Overexpression & {$[29]$} \\
\hline Squamous cell carcinoma & Overexpression & {$[29]$} \\
\hline Ovarian cancer & Overexpression & {$[29]$} \\
\hline Glioma & Overexpression & {$[29]$} \\
\hline Breast cancer & Overexpression & {$[29]$} \\
\hline Lung cancer & Overexpression & {$[29]$} \\
\hline
\end{tabular}

Table 1: Published literature showing correlation of BMI1 overexpression with different cancer types assessed in in vitro and in vivo models. has been reported to regulate p16INK4a and cyclin D1 status, and associate with type and behavior of tumor in breast cancer [14]. Song et al. has shown that the overexpression of BMI1 in nasopharyngeal epithelial cells specifically target the $\mathrm{pRb}$ signalling pathway by downregulation of p16INK4a, resulting in cell immortalization [10]. Studies have also demonstrated that the high expression of BMI11 promotes prostate tumorigenesis by inhibiting p16INK4A and p14ARF expression, which ultimately leads to abnormal cell proliferation as shown in Figure 1 [38]. Besides the telomerase activation, a normal DNA damage response was sustained by the BMI1-immortalized nasopharyngeal epithelial cells [12]. Accumulating evidence has revealed that inhibition of BMI1 could facilitate efficacy to cisplatin based therapy by inducing apoptosis through the activation of DNA damaging response [6]. Song et al. has shown that Epithelial Mesenchymal Transition (EMT) is associated to upregulation of BMI, which enhances the motility and invasiveness of human nasopharyngeal epithelial cells, while as suppressing endogenous BMI1 expression reversed EMT and reduces motility [28].

\section{BMI1 and Prostate Cancer}

$\mathrm{CaP}$ is heterogenous disease, which ranges from indolent localized tumors to aggressive metastatic diseases [39]. The common treatment options available for metastatic $\mathrm{CaP}$ are traditional cytotoxic chemotherapies, which includes castration. However, these therapies do not significantly prolong the survival of patients and majority of the patients exhibit local or distant recurrence of hard-to-treat CastrationResistant Prostate Cancer [CRPC]. Despite chemotherapy, CRPC patients display characteristic progression and acquire chemoresistant disease [40]. The paucity of knowledge about the molecular mechanism involved in the development of chemoresistance is a major stumbling block in the management of CaP. Therefore, the identification and targeting certain crucial molecules involved in acquiring chemoresistance would be a significant achievement in tailoring the therapeutic strategies to prevent this fatal disease. Recent cancer genomic studies have revealed the mechanisms underlying the chemoresistance and sparing of prostate tumor cells after cancer therapy. Several reports have documented the involvement of certain genes, including the Polycomb gene repressor family, which has been involved in various cancers including prostate cancer.

The expression of BMI1 levels are higher in malignant than normal prostatic tissues, and there is significant increase in the expression as the disease progresses from low-grade to high-grade [41]. Recent studies have shown that there is a significant upregulation BMI1 in tumors with higher Gleason scores, while as in lower grade prostate cancer samples, the presence of BMI1 is of prognostic significance for prostatespecific antigen recurrence [42]. Genomic and microarray analysis have found that overexpression of BMI1 in prostatic cancer tissues is often a predictive marker for metastasis and dismal therapeutic outcome [29]. The higher tumor initiating capacities of prostate cancer cells at the tumor site has also been an attributive of higher expression of BMI1 [29]. BMI1 inhibition decreases the growth of aggressive PTEN-deletion induced prostate cancer and protects prostate cells from FGF10 driven hyperplasia [43].

Altogether, these data provide evidences that intensive expression of BMI1 might be important in the acquisition of an invasive and/or aggressive CRPC, and BMI1 has the potential to be an independent molecular marker and therapeutic target of patients with a poor prognostic outcome.

In addition, Glinsky et al. has found the BMI1- driven 11-gene signature representing a stem cell-resembling expression profile in 


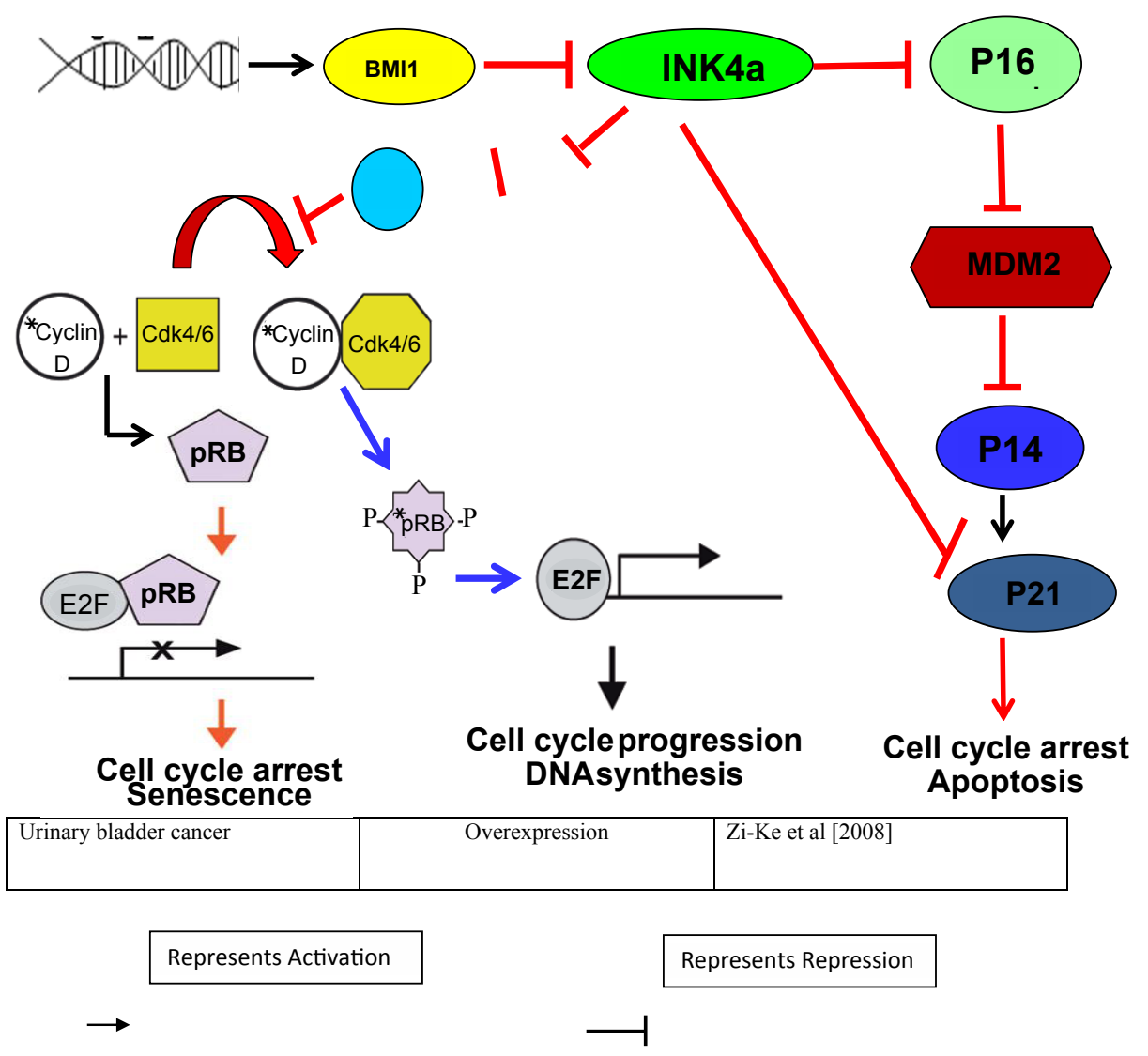

Figure 1: Role of BMI1 in promoting the prostate tumorigenesis by regulating the Ink4a/Arf signalling Pathway. This figure shows how BMI1 helps in the mediation of transcriptional repression at the Ink4a/Arf locus. The repression of Ink4a leads to the inactivation of P16 and P14 proteins, which in turn suppresses the downstream target P53 and formation of CyclinD/CDK complex. This whole mechanism during normal expression of BMI1 leads to downstream repression of cell cycle and oncogenic pathways.

prostate cancer [29]. The prognostic significance of these 11-gene signature was further validated as a measure of therapy-outcome sets in clinical samples obtained from 1,153 cancer patients diagnosed with eleven different types of cancer, including five epithelial malignancies (prostate, breast, lung, ovarian, and bladder cancers] and five nonepithelial malignancies [lymphoma, mesothelioma, medulloblastoma, glioma, and acute myeloid leukemia). These findings are indicative of BMI1 regulated molecular mechanisms, which are involved in the pathogenesis of several human cancers.

\section{BMI1 in Prostate Cancer Therapeutics}

The therapeutic potential of BMI1 in cancer therapy is exemplified by various recent studies. Griffith et al. has investigated the potential of BMI1 in sensitizing the breast cancer cells to radiation therapy [44]. Similarly, another recent study has demonstrated that tumor growth and proliferation is suppressed by downregulating the BMI1 expression in breast cancer stem cells [45]. Despite of cytotoxic chemotherapy and castration, there has been a minimal improvement in the prognosis of $\mathrm{CaP}$ patients. Additionally, $30-50 \%$ of $\mathrm{CaP}$ patients exhibit a local or distant relapse of disease resulting in most deaths. The dismal outcome of therapeutic strategies is associated with heterogenous nature of individuals and tumors, and treatment failure is often attributed to chemoresistance. The current available clinical diagnostic and prognostic biomarkers are not efficient enough to be representative of these hard-to-treat tumor cells, and therefore are not appropriate for the treatment of choice. Consequently, unraveling the molecular mechanisms that govern the chemoresistance and tumor heterogeneity could be very useful in identifying the potential targets for individual treatment. Siddique et al. demonstrated that silencing BMI1 reduces the growth and proliferative potential of different $\mathrm{CaP}$ cells, and increases the responsiveness of chemoresistant $\mathrm{CaP}$ to various clinical chemotherapeutic agents like bicalutamide/casodex, docetaxel and cisplatin [40]. Furthermore, using a mouse xenograft model, they showed that targeting BMI1 in chemoresistant cells sensitizes them to docetaxel therapy, and that the success of docetaxel therapy in the xenograft mouse model was highly dependent on the level of BMI1. This suggests that i) targeting BMI1 should be a part of therapeutic strategy to combat chemoresistant cancer, and ii) BMI1-specific interventions may provide opportunities to enhance the efficacy of chemotherapy in a large group of prostate cancer patients.

In addition, Bansal et al. and others have recently demonstrated that primary prostate cancer site is enriched with a population of cells with self-renewal and tumorigenic potential [46], known as tumor initiating cells [TICs]. The resistance to therapy conferred by these TICs is often linked to the tumor relapse. Several studies have shown that the selfrenewal capacity of these TICs, which has been attributive of BMI1 overexpression, is involved in prostate cancer initiation and progression 
[42]. Therefore, suggests BMI1 as an attractive therapeutic target in eradicating the TICs to prevent the chemoresistance and tumor relapse.

Genetic studies have not been able to determine the exact mechanism of BMI1 overexpression in various cancers including prostate. However, there are several findings which suggest that the overexpression of BMI1 does not always coincide with gene amplification, but nevertheless they may contribute to the pathogenesis of various malignant cancer types [47]. Accumulating evidence has revealed the discrepancy between BMI1 protein expression and BMI1 mRNA in various cancer tissues compared to normal tissues [48], indicating an additional possible genetic alteration might impose a positive effect on BMI1 protein expression. Emerging evidences suggest that certain miRNAs are dysregulated in the pathogenesis of many cancers and miR128 was found to be underexpressed in prostate tumor initiating cells. Jin et al. showed that the exogenously introduced miRNA-128 in prostate xenograft mouse models reduces the BMI1 protein levels, which led to significant suppression of tumor regeneration [49]. Based on the convincing evidences (which suggest the critical role of BMI1 in CaP growth and proliferation), using BMI1 as a target for anticancer therapy seems to have a promising potential.

\section{Concluding Remarks}

Currently, there is a scarcity of knowledge about the potential targets (Which are overexpressed in $\mathrm{CaP}$ formation and progression) involved in the pathogenesis of $\mathrm{CaP}$, resulting in refractory and recurrent disease relapse. The complexity of tumor heterogeneity and mechanisms underlying CSCs self-renewal has paved a new perspective of $\mathrm{CaP}$ therapeutics. It has been quite evident that BMI1 is a distinct oncogene and plays pivotal role in cancer stem cell self-renewal and tumorigenesis of CaP. The aberrant expression of BMI1 has been validated and correlated with various clinical characteristics and survival outcomes in a varied set of human malignancies, including CaP. Consequently, identifying the effective small molecule inhibitors that reduce the BMI1 protein levels will target CSCs and may provide more long-lasting therapeutic benefit when combined to existing therapeutic strategies. However, the risk of toxicity to normal cells associated with targeting BMI1 over the passage of treatment is a question which remains to be fully addressed. Altogether, these observations suggest an attractive therapeutic potential of $\mathrm{BMI}$ in the management of $\mathrm{CaP}$. Nevertheless, the underlying molecular events leading to oncogenic activation of BMI1 in the development of CaP, still needs to be fully comprehended to qualify BMI1 as a therapeutic target.

\section{Conflict of Interest}

The contributing Authors have no financial or any non-financial competing interests.

\section{References}

1. Siegel R, Naishadham D, Jemal A (2012) Cancer Statistics. Cancer J Clin 62:10-29. [PubMed]

2. Catalona WJ, Smith DS (1998) Cancer recurrence and survival rates after anatomic radical retropubic prostatectomy for prostate cancer: intermediate term results. J Urol 160: 2428. [PubMed]

3. Pound CR, Partin AW, Eisenberger MA, Chan DW, Pearson JD, et al. (1999) Natural history of progression after PSA elevation following radical prostatectomy. JAMA 281:1591-1597. [PubMed]

4. Kotb AF, Elabbady AA (2011) Prognostic factors for the development of biochemical recurrence after radical prostatectomy. Prostate Cancer 485189. [PubMed]

5. Parray A, Siddique HR, Nanda S, Konety BR, Saleem M (2012) Castration resistant prostate cancer: potential targets and therapies. Biologics 6: 267-276. [PubMed]

6. Wang E, Bhattacharyya S, Szabolcs A, Rodriguez-Aguayo C, Jennings NB, et al. (2011) Enhancing chemotherapy response with BMI1 silencing in ovarian cancer. PLoS One 6: e17918. [PubMed]

7. Huber GF, Albinger-Hegyi A, Soltermann A, Roessle M, Graf N, et al. (2011) Expression patterns of BMI1 and p16 significantly correlate with overall disease specific, and recurrence-free survival in oropharyngeal squamous cell carcinoma. Cancer 117: 4659-4670. [PubMed]

8. Siddique HR, Saleem M (2012) Role of BMI1, a stem cell factor, in cancer recurrence and chemoresistance: preclinical and clinical evidences. Stem Cells 30: 372-378. [PubMed]

9. Cao L, Bombard J, Cintron K, Sheedy J, Weetall ML, et al. (2011) BMI1 as a novel target for drug discovery in cancer. J Cell Biochem 112: 2729-2741. [PubMed]

10. Song LB, Zeng MS, Liao WT (2006) Bmi-1 is a novel molecular marker of nasopharyngeal carcinoma progression and immortalizes primary human nasopharyngeal epithelial cells. Cancer Res 66: 6225-6232. [PubMed]

11. Marquardt JU, Factor VM, Thorgeirsson SS (2010) Epigenetic regulation of cancer stem cells in liver cancer: current concepts and clinical implications. J Hepatol 53: 568-577. [PubMed]

12. Crea F, Serrat MAD, Hurt EM, Thomas SB, Danesi R, et al. (2011). BMI1 silencing enhances docetaxel activity and impairs antioxidant response in prostate cancer. Int J Cancer 128: 1946-1954. [PubMed]

13. Benard A, Goossens-Beumer IJ, van Hoesel AQ, Horati H, et al. (2014) Prognostic value of polycomb proteins EZH2, BMI1 and SUZ12 and histone modification H3K27me3 in colorectal cancer. PLoS One 9: e108265. [PubMed]

14. Wang H, Liu H, Li X, Jing Zhao, Hong Zhang, et al. (2014) Estrogen receptor a-coupled Bmi1 regulation pathway in breast cancer and its clinical implications. BMC Cancer 14: 122. [PubMed]

15. Park IK, Morrison SJ, Clarke MF (2004). Bmi1, stem cells, and senescence regulation. J Clin Invest 113: 175-179. [PubMed]

16. Engelsen IB, Mannelqvist M, Stefansson IM, Carter SL, Beroukhim R, et al (2008) Low BMI-1 expression is associated with an activated BMl-1-driven signature, vascular invasion, and hormone receptor loss in endometrial carcinoma. Br J Cancer.;98(10):1662-1669. [PubMed]

17. Allegra E, Puzzo L, Zuccalà V, Trapasso S, Vasquez E, et al. (2012) Nuclear BMI-1 expression in laryngeal carcinoma correlates with lymph node pathological status. World J Surg Oncol 10: 206.

18. Alkema MJ, Wiegant J, Raap AK, Berns A, van Lohuizen M (1993) Characterization and chromosomal localization of the human proto-oncogene BMI-1. Hum Mol Gene 2: 1597-1603. [PubMed]

19. Raaphorst FM (2005) Deregulated expression of Polycomb-group oncogenes in human malignant lymphomas and epithelial tumors. Hum Mol Genet 14 R93-R100. [PubMed]

20. Li Z, Cao R, Wang M, Myers MP, Zhang Y, et al. (2006). Structure of a Bmi1-Ring1B polycomb group ubiquitin ligase complex. J Biol Chem. 2006; 281:20643e20649. [PubMed]

21. Cohen KJ, Hanna JS, Prescott JE, Dang CV (1996) Transformation by the Bmi-1 oncoprotein correlates with its subnuclear localization but not its transcriptional suppression activity. Mol Cell Biol 16: 5527-5535. [PubMed]

22. Park IK, Qian D, Kiel M, Becker MW, Pihalja M, et al. (2003) Bmi-1 is required for maintenance of adult self-renewing haematopoietic stem cells. Nature 423 : 302-305. [PubMed]

23. Abd El hafez A, El-Hadaad HA (2014) Immunohistochemical expression and prognostic relevance of Bmi-1, a stem cell factor, in epithelial ovarian cancer. Ann Diagn Pathol 18: 58-62.

24. Lessard J, Schumacher A, Thorsteinsdottir U, van Lohuizen M, Magnuson T, et al. (1999) Functional antagonism of the Polycomb-Group genes and BMI1 in hemopoietic cell proliferation. Genes Dev 13: 2691-2703. [PubMed]

25. Leung C, Lingbeek M, Shakhova O, Liu a, Tanger E, et al. (2004) BMI1 is essential for cerebellar development and is overexpressed in human medulloblastomas. Nature 428: 337-341. [PubMed] 
Citation: Beigh FH, Syeed N, Maqbool M, Majumdhar RS (2017) Targeting Stem Cell Protein BMI1; A Potential Therapeutic Approach for Prostate Cancer Therapy. J Stem Cell Res Ther 7: 388. doi: 10.4172/2157-7633.1000388

Page 5 of 5

26. Molofsky AV, He S, Bydon M, Morrison SJ, Pardal R (2005) BMI1 promotes neural stem cell self-renewal and neural development but not mouse growth and survival by repressing the p16Ink4a and p19Arf senescence pathways. Genes Dev 19: 1432-1437. [PubMed]

27. Facchino S, Abdouh M, Chatoo W, Bernier G (2010) BMI1 confer radioresistance to normal and cancerous neural stem cells through recruitment of the DNA damage response machinery. J Neurosci 30: 10096e10111. [PubMed]

28. Song LB, Li J, Liao WT, Feng Y, Yu CP, et al. (2009) The polycomb group protein BMI1represses the tumor suppressor PTEN and induces epithelialmesenchymal transition in human nasopharyngeal epithelial cells. J Clin Invest 119: 3626-3636. [PubMed]

29. Glinsky GV, Berezovska O, Glinskii AB (2005) Microarray analysis identifies a death-from-cancer signature predicting therapy failure in patients with multiple types of cancer. J Clin Invest 115: 1503-1521. [PubMed]

30. Zeng J, Ruan J, Luo L, Shi J, Cui Q, et al. (2014) Molecular portraits of heterogeneity related to cancer stem cells in human ovarian cancer. Int $J$ Gynecol Cancer 24: 29-35. [PubMed]

31. Pardal R, Clarke MF, Morrison SJ (2003) Applying the principles of stem-cell biology to cancer. Nat Rev Cancer 3: 895-902. [PubMed]

32. Alamodi AA, Eshaq AM, Hassan SY, Al Hmada Y, El Jamal SM, et al. (2016) Cancer stem cell as therapeutic target for melanoma treatment. Histol Histopathol 15: 11791. [PubMed]

33. Zhang F, Sui L, Xin T (2008) Correlations of Bmi-1 expression and telomerase activity in ovarian cancer tissues. Exp Oncol 30: 70-74. [PubMed]

34. Allegra E, Trapasso S, Pisani D, Puzzo L (2014) The role of BMl1 as a biomarker of cancer stem cells in head and neck cancer: a review. Oncology 86: 199-205. [PubMed]

35. Heffner M, Fearon DT (2007) Loss of T cell receptor-induced Bmi-1 in the KLRG1(+) senescent CD8(+) T lymphocyte. Proc Natl Acad Sci USA 104: 13414-13419. [PubMed]

36. Bhattacharya R, Nicoloso M, Arvizo R, Wang E, Cortez A, et al. (2009) MiR$15 \mathrm{a}$ and MiR-16 control Bmi-1 expression in ovarian cancer. Cancer Res 69: 9090-9095. [PubMed]

37. Valk-Lingbeek ME, Bruggeman SW, Van LM (2004) Stem cells and cancer; the polycomb connection. Cell 118: 409-418. [PubMed]

38. Fan C, He L, Kapoor A, Gillis A, Adrian P, et al. (2008) Biochimica et Biophysica Acta 1782 pp: 642-648.
39. Mahon KL, Henshall SM, Sutherland RL, Horvath LG (2011) Pathways of chemotherapy resistance in castration-resistant prostate cancer. Endocr Relat Cancer 18: R103-123. [PubMed]

40. Catalona WJ, Smith DS (2011) Cancer recurrence and survival rates afte anatomic radical retropubic prostatectomy for prostate cancer: intermediatetermresults. J Urol 1998; 160: 2428. [PubMed]

41. Siddique HR, Parray A, Rohinton S. Tarapore, Wang L, Mukhtar H, et al. (2013) BMI1 Polycomb Group Protein Acts as a Master Switch for Growth and Death of Tumor Cells: Regulates TCF4-Transcriptional Factor-Induced BCL2 Signaling. Plos One 8: e60664. [PubMed]

42. van Leenders GJ, Dukers D, Hessels D, van den Kieboom SW, Hulsbergen CA, et al. (2007) Polycomb-grouponcogenes EZH2, BMI1, and RING1 are overexpressed inprostate cancer with adverse pathologic and clinical features. Eur Urol 52: 455-463. [PubMed]

43. Lukacs RU, Memarzadeh S, Wu H, Witte ON (2010) Bmi-1 is a crucialregulator of prostate stem cell self-renewal and malignanttransformation. Cell Stem Cell 7: 682-693. [PubMed]

44. Griffith J, Andrade D, Mehta M, Berry W, Benbrook DM, et al. (2017) Silencing BMI1 radiosensitizes human breast cancer cells by inducing DNA damage and autophagy. Oncol Rep. 37: 2382-2390. [PubMed]

45. Srinivasan M, Bharali DJ, Sudha T, Khedr M, Guest I, et al. ( 2017) Downregulation of Bmi1 in breast cancer stem cells suppresses tumor growth and proliferation. Oncotarget. [PubMed]

46. Bansal N, Davis S, Tereshchenko I, Budak-Alpdogan T, Zhong H, Stein MN (2014) Enrichment of human prostate cancer cells with tumor initiating properties in mouse and zebrafish xenografts by differential adhesion. Prostate 74: 187-200. [PubMed]

47. Gui T, Bai H, Zeng J, Zhong Z, Cao D, et al. (2014) Tumor heterogeneity in the recurrence of epithelial ovarian cancer demonstrated by polycomb group proteins. Onco Targets Ther 7: 1705-1716. [PubMed]

48. Qin ZK, Yang JA, Ye YL, Zhang X, Xu LH, et al. (2009) Expression of Bmi-1 is a prognostic marker In bladder cancer. BMC Cancer 9: 61. [PubMed]

49. Jin M, Zhang T, Liu C, Badeaux MA, Liu B, et al. (2014) miRNA-128 suppresses prostate cancer by inhibiting BMI-1 to inhibit tumor-initiating cells. Cancer Res 74: 4183-4195. [PubMed] 